\title{
Patient participation in care safety: Primary Health Care professionals' perception
}

\author{
Participação do paciente na segurança do cuidado: percepção de profissionais da Atenção Primária à Saúde \\ Participación del paciente en la seguridad de la atención: percepción de los profesionales de la Atención Primaria de Salud
}

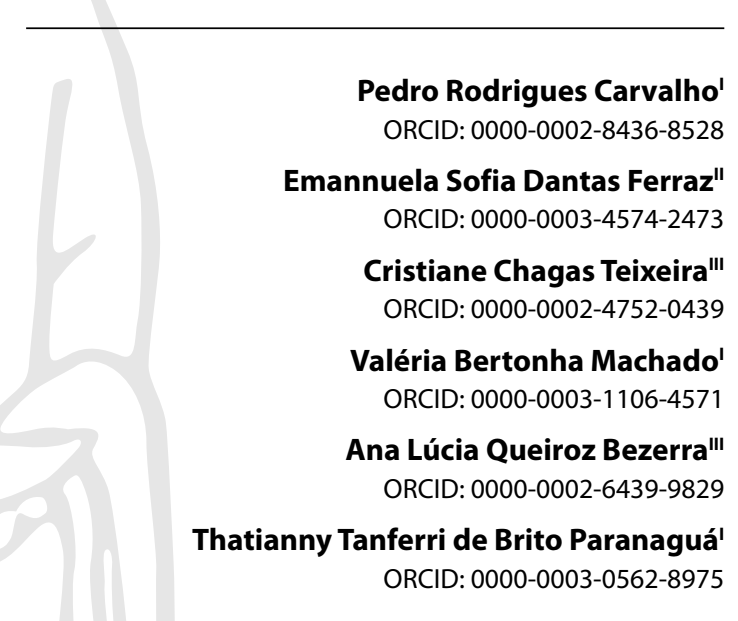

'Universidade de Brasília. Brasília, Distrito Federal, Brazil. "Secretaria de Saúde do Distrito Federal. Brasília, Distrito Federal, Brazil. "'Universidade Federal de Goiás. Goiânia, Goiás, Brazil.

How to cite this article: Carvalho PR, Ferraz ESD, Teixeira CC, Machado VB, Bezerra ALQ, Paranaguá TTB. Patient participation in care safety: Primary Health Care professionals' perception.

Rev Bras Enferm. 2021;74(2):e20200773. https://doi.org/10.1590/0034-7167-2020-0773

Corresponding author:

Thatianny Tanferri de Brito Paranaguá

E-mail: paranagua@unb.br

EDITOR IN CHIEF: Antonio José de Almeida Filho ASSOCIATE EDITOR: Mitzy Reichembach

Submission: 07-09-2020 Approval: 12-09-2020

\begin{abstract}
Objectives: to analyze health professionals' perception about the meaning and practice of patient involvement in care safety in Primary Health Care. Methods: this is an exploratory, qualitative study, developed with 22 professionals in the Federal District, Brazil. A semistructured interview was conducted between October and November/2018. Content analysis was carried out according to Bardin. Results: nurses, physicians, dentists, among others, participated. The following categories emerged: Meaning of patient involvement in care safety; Factors intervening in patient involvement in care safety; Strategies for patient involvement in care safety; Qualification for patient involvement in care safety. Final Considerations: the meaning of patient involvement for care safety was associated with co-responsibility and patient-centered care. Professionals' practice revealed intervening factors and the use of involvement strategies. A gap was identified in training on patient involvement in care safety. Descriptors: Patient Participation; Professional Practice; Knowledge Management for Health Research; Patient Safety; Primary Health Care.
\end{abstract}

\section{RESUMO}

Objetivos: analisar a percepção dos profissionais de saúde sobre o significado e a prática do envolvimento do paciente na segurança do cuidado na Atenção Primária à Saúde. Métodos: estudo exploratório, qualitativo, desenvolvido com 22 profissionais no Distrito Federal, Brasil. Realizou-se entrevista semiestruturada entre outubro e novembro/2018. Realizouse análise de conteúdo, conforme Bardin. Resultados: participaram enfermeiros, médicos, odontólogos, dentre outros. Revelaram-se as categorias: Significado do envolvimento do paciente na segurança do cuidado; Fatores intervenientes ao envolvimento do paciente na segurança do cuidado; Estratégias de envolvimento do paciente na segurança do cuidado; Qualificação para o envolvimento do paciente na segurança do cuidado. Considerações Finais: o significado do envolvimento do paciente para a segurança do cuidado foi associado à corresponsabilização e ao cuidado centrado no paciente. A prática dos profissionais revelou fatores intervenientes e uso de estratégias de envolvimento. Identificou-se lacuna na formação sobre envolvimento do paciente na segurança do cuidado.

Descritores: Participação do Paciente; Prática Profissional; Gestão do Conhecimento para a Pesquisa em Saúde; Segurança do Paciente; Atenção Primária à Saúde.

\section{RESUMEN}

Objetivos: analizar la percepción de los profesionales de la salud sobre el significado y la práctica del involucramiento del paciente en la seguridad de la atención en Atención Primaria de Salud. Métodos: estudio exploratorio, cualitativo, desarrollado con 22 profesionales del Distrito Federal, Brasil. Se realizó una entrevista semiestructurada entre octubre y noviembre/2018. Se realizó análisis de contenido, según Bardin. Resultados: participaron enfermeras, médicos, dentistas, entre otros. Se revelaron las siguientes categorías: Significado de la participación del paciente en la seguridad de la atención; Factores que intervienen en la implicación del paciente en la seguridad asistencial; Estrategias para la participación del paciente en la seguridad de la atención; Calificación para la participación del paciente en la seguridad de la atención. Consideraciones Finales: el significado de la implicación del paciente para la seguridad asistencial se asoció con la corresponsabilidad y la atención centrada en el paciente. La práctica de los profesionales reveló factores intervinientes y el uso de estrategias de participación. Se identificó una brecha en la capacitación sobre participación del paciente en la seguridad de la atención.

Descriptores: Participación del Paciente; Práctica Profesional; Gestión del Conocimiento para la Investigación en Salud; Seguridad del Paciente; Atención Primaria de Salud. 


\section{INTRODUCTION}

Global attention to patient safety, defined as reducing, to an acceptable minimum, the risk of unnecessary harm associated with health care $^{(1)}$, stems from the finding that $10 \%$ of people in need of health care suffer adverse events ${ }^{(2)}$. It is estimated that $31 \%$ of the adverse events detected during hospitalization occurred before admission, and it is possible that they occurred in Primary Health Care $(\mathrm{PHC})^{(3)}$.

The analysis of 2,178 reports from England and Wales identified 2,191 incidents in home care and community pharmacies ${ }^{(4)}$. In low or middle income countries, errors in the context of PHC and outpatient care can reach $25 \%$ to $40 \%$ of the care provided; of these, $80 \%$ are considered preventable ${ }^{(5)}$. In Brazil, a study carried out in 13 Basic Health Units (BHUs) identified the occurrence of incidents that resulted in damage to patients, associated with failures in care, management, and communication ${ }^{(6)}$. In Manaus, patient safety incidents were mainly related to errors in treatment and management of medical records. Of the 105 notifications, $37 \%$ recorded damage, including two deaths ${ }^{(7)}$.

In order to understand the risks in patients under PHC, the magnitude and nature of preventable damage, due to unsafe practices in these environments, the World Health Organization (WHO), together with the Pan American Health Organization, has encouraged investigations in this area. area and declared safe primary care as a challenge to be faced by health institutions ${ }^{(8)}$.

In order to generate better care results, in this perspective of harm reduction, the patient's involvement in his own care has gained notoriety. The Patients for Patient Safety program, created by $\mathrm{WHO}$, encourages this involvement and requires collaboration and partnership between patients, professionals, managers and victims of incidents in the processes of improving safety ${ }^{(9)}$. It also encourages patients to be at the center of health care ${ }^{(9)}$.

Patient-centered care takes into account the person with their preferences and needs in an individualized, respectful way, establishing a collaborative relationship between professional and patient ${ }^{(10)}$. In this context, patient involvement in care stands out, defined as patients' participation in decision-making on health issues, including active participation in the planning, monitoring and assessment of their care ${ }^{(11)}$.

In addition to promoting care self-management, patient involvement increases care safety and has been encouraged as a way to minimize the occurrence of incidents ${ }^{(12)}$. However, it is observed that safety is an aspect that does not receive special attention from patients and still has an incipient discussion among health professionals ${ }^{(13)}$, especially in $\mathrm{PHC}$. On the other hand, it is observed that professionals and patients recognize patient involvement as an important factor to increase care security ${ }^{(13)}$.

It is known that patient involvement for care safety is still a challenge. In PHC, evidence about patient safety and patient involvement for care safety is scarce. Considering patients as an important barrier to avoid security incidents and that, in the context of PHC, patients must be the leaders of care for continuity of the therapeutic process, it is asked: what is health professionals' perception about the meaning and practice of patient involvement in care safety in the context of PHC?

\section{OBJECTIVES}

To analyze health professionals' perception about the meaning and practice of patient involvement in care safety in Primary Health Care.

\section{METHODS}

\section{Ethical aspects}

This research was approved by the Research Ethics Committee. All ethical aspects followed Resolution 466/12 of the Brazilian National Health Council (CNS - Conselho Nacional de Saúde). All participants signed the Informed Consent Form (TCLE) and authorization document for voice use. The reports were organized numerically in order of participation in order to guarantee confidentiality regarding exposure of participants'identity, assigning letter I for an interview, followed by an ordinal number.

\section{Type of study}

This is an exploratory and descriptive study with a qualitative approach. The Consolidated Criteria for Reporting Qualitative Research Checklist (COREQ) was used to describe the methodology.

\section{Study setting}

The study was developed in five PHC units, located in the Federal District, Brazil.

\section{Data source}

The population was composed of health professionals belonging to the 24 Family Health Teams linked to the selected units. Professionals who work at the unit for a minimum period of six months, as they consider their perception in relation to the organizational culture relevant to the practice of patient involvement in care were included. Health professionals who were removed from their duties during the data collection period were excluded from the survey.

Twenty-two health professionals participated in the study, selected by convenience. Theoretical data saturation sampling technique was used, which consists in interrupting data collection based on the observation that no new elements would appear in the field of observation to support the desired theorization ${ }^{(14)}$. During professional selection, five refused to participate because they were busy at the time of the approach.

\section{Data collection and organization}

The data collection instrument was developed in order to assess the perception, meaning and importance attributed by health professionals regarding patient involvement in care safety. A pilot test was carried out with 8 professionals from Basic Health Units, who were not included in this study, in order to assess the instrument's clarity and objectivity as well as the ability to achieve the research objectives. The final instrument was structured in two parts. The first aimed to investigate participants' professional profile and the 
second part covered the following guiding questions about patient involvement in care practices from the perspective of patient safety: for you, what is the meaning of patient involvement in their own safety during care? To what extent do you consider this patient participation in issues involving your own care to be important? How do you involve patients in the care safety you provide? How do you perceive this practice of involving patients in care safety by the health team of this institution? In your opinion, what facilitates and what hinders the practice of patient involvement in care? Do you feel able to involve patients in care safety? Why? What support does the institution offer for the practice of patient involvement in patient safety?

Data were collected through individual interviews, only with the presence of the interviewer and professional, in October and November 2018, in the workplace of each interviewee. To avoid data loss, the interviews' content was recorded after participants' consent. Each interview lasted an average of fifteen minutes. The person responsible for conducting the interviews was a nursing student, a member of a research group in health service management, linked to a line of research in the area of patient safety; he was close to the research topic and understood the principles that guide the interview technique for obtaining data. The interviewer did not have any kind of previous relationship with any of the interviewees.

\section{Data analysis}

All data were transcribed and submitted to content analysis according to Bardin's reference ${ }^{(15)}$, following the stages of organization and analysis, structured in three chronological phases: a) Pre-analysis, which consisted of skimming the research corpus for knowledge of the material; then, the corpus of analysis was selected, guaranteeing completeness, representativeness, homogeneity, exclusivity, and relevance of content to the objectives of the study; the indexes were referenced, with the guiding question of the research as a guide; finally, the texts were organized by standardization and equivalence; b) Material exploration, which consisted of analysis itself, where record unit coding was carried out, by means of cutouts that were classified and grouped considering the semantics; later, meanings were assigned, proceeding with categorization; c) Treatment of results, where inference and interpretation of the data highlighted in the analysis was carried out.

Four thematic categories emerged: Meaning of patient involvement in care safety; Factors intervening in patient involvement in care safety; Strategies for patient involvement in care safety; Qualification for patient involvement in care safety.

\section{RESULTS}

Twenty-two health professionals participated in the study. The characterization data are described in Table 1.

The age of participants ranged from 25 to 70 years, with an average of 43.8 years $(S D=11.3)$. Training time ranged from 10 months to 35 years, time of professional experience, from 6 months to 35 years and job tenure, from 6 months to 25 years. As for carrying out courses, all participants stated that they had not received any course in the patient safety work unit and only two $(9.1 \%)$ took it on their own.
Table 1 - Characterization of Primary Health Care professionals, Brasília, Distrito Federal, Brazil, 2018, $(\mathrm{N}=22)$

\begin{tabular}{lcc}
\hline Variables & $\mathbf{n}$ & $\%$ \\
\hline Sex & & \\
$\quad$ Female & 19 & 86.4 \\
$\quad$ Male & 03 & 13.6 \\
Academic training & & \\
$\quad$ Nurse & 06 & 27.3 \\
Nursing technician & 06 & 27.3 \\
Physician & 05 & 22.7 \\
Others & 05 & 22.7 \\
Degree & & \\
Specialization & 11 & 50.0 \\
Undergraduate degree & 04 & 18.2 \\
Vocational training & 05 & 22.7 \\
$\quad$ Master's degree & 02 & 9.1 \\
Function & & \\
Assistance & & \\
Assistance and Management & 16 & 72.7 \\
$\quad$ Management & 05 & 22.7 \\
Total & 01 & 4.6 \\
\hline
\end{tabular}

\section{Meaning of patient involvement in care safety}

For PHC health professionals, patient involvement in care safety is strongly associated with patient co-responsibility. The reports showed that patients need to understand that they are the leaders of their health-disease process and needs to be active and autonomous individuals:

They are co-responsible for this process, security. Not only in the risk of falling, but also in the use of medications, in the warning signs, that they have to understand when it is getting worse. (122)

[...] we call co-responsibility, a matter of awareness; talking to patients, how important they are in that process. (119)

[...] to be co-responsible for their care, not least because several diseases, such as diabetes, hypertension, these chronic diseases that require changes in diet, changes in daily habits. (I11)

[...] much of the percentage of the problem is solved by themselves, taking their own care. (I13)

[...] giving autonomy to patients, not leaving patients so dependent on the teams. (19)

In this process, the importance of patient-centered care was highlighted. The reports revealed that individualized care favors health professionals to understand patients' real needs and, consequently, greater patient adherence to the proposed care:

[...] because what is the use of talking about food, if it's not their will, if they can't buy it, if they don't like it, they don't understand that they have this role. (122)

[...] bringing them up to date with the problem, their problem, and seeing how they could change. Of course, we are not going to get him to make a change overnight, a radical change. But under their conditions, theirpace of life, what can they do to improve that situation. (I11) 
Patient participation in care safety: Primary Health Care professionals' perception Carvalho PR, Ferraz ESD, Teixeira CC, Machado VB, Bezerra ALQ, Paranaguá TTB.

It was also pointed out that patient involvement is important for care safety as it promotes patients' commitment to the execution of the received and agreed guidelines for favoring the understanding of their health-disease process and, consequently, being able to manage the possible risks involved in their health situation:

Their commitment to following our guidelines, so they maintain their safety. (I3)

[...] when we attend prenatal care, the first thing we say is "you can't smoke, harm the baby, stop smoking". But this agreement of her to understand why not, what can she start, what are the goals? Can you cut down on a cigarette? Okay, cut down a cigarette. Ah, I can cut two. Then decrease two. At that moment, when you agree, users understand that it is important and they manage to agree with you, that becomes, for them, visible, palpable. (122)

[...] when they get involved, they have an optimization of this care, because if they don't get involved, the risks, they occur more often. (I14)

You can prevent a lot of disease, a lot of complications because of that, so patient involvement is essential. (I8)

\section{Factors intervening in patient involvement in care safety}

Several factors were identified that can interfere, positively or negatively, in patient involvement process for care safety. The social determinants were emphasized, with an emphasis on level of education, as it affects patients' understanding of the guidelines:

We have [...] clear differences when patients are able to get involved, when they are able to get involved and when they are not. We have abig difference in their prognosis, in the immediate result of treatment. (12)

[...] we have a lot of difficulty, sometimes, for patients to understand what we say [...] there is the issue of illiteracy. These patients often cannot understand the prescription. (I17)

The issue of education level, culture, family issue. So, all factors influence. Financial issue. So, all of this has a little impact on care, so we can explain. (I14)

The reports showed the importance of establishing a link to favor patient involvement in care and knowledge of patients' needs by the health team:

It is the bond that patients create with the unit. When they have a relationship with nurses, with technicians, with physicians, with the whole team. They feel welcomed and return. (119)

It was also revealed that the Family Health Strategy (FHS) consists of a favorable environment for the practice of patient involvement in care. It was highlighted that FHS promotes closer approximation and involvement of the service with the reality and patients' needs through territorialization. However, the reports pointed out that there is still some resistance to changing the culture in the service, which can hinder the process of making patients active:

There was a big change with the Family Health Strategy, there was a big paradigm shift. And it helps us a lot to know patients, territorialization also helps us to know patients' local reality, where they live, how they live, what their social conditions are like. (12)

[...] but we still have this model, which is still very medical. Centralized, of centralized assistance, but it has tried to change. (122)

[...] we have this difficulty a lot because we are very 'prescriptive' and physicians also have this issue of authority. (117)

The culture of medicalization of health and popular knowledge appeared as intervening factors, which prevent a more proactive behavior of patients for care management:

It is still difficult for patients to feel responsible for treatment. They wait, they think it's just medication. It is very complex to change the behavior. (I11)

The stories they hear from neighbors, mothers-in-law, grandparents, the very popular knowledge that we have to value [...] but that they often do not accept other knowledge. Sometimes a child has difficulty breastfeeding and the grandmother has already gone and gave her milk, already gave the newborn a tea with sugar and thinks it is great because she slept all night. (118)

The reports of health professionals revealed aspects related to organizational support that can also hinder or favor the commitment to patient involvement in care safety, with emphasis on the time for consultation and lack of professionals in the health team. It was revealed that actions for patient involvement in care are related to professionals' attitudes in making things happen and not to institutional culture:

In terms of consultation time, as there is little time, sometimes patients leave without knowing exactly how it should be used [medication]. In a fifteen-minute consultation, it is sometimes impossible, very difficult. (I17)

[...] we have a lacking team, we are in a team restructuring, we are without a physician, a new nurse is coming, we are a bit lacking. (I20)

Ithink there is more support from professionals than from the institution itself. What I understand is that it is not for the institution, it is for professionals, for the time of service, listening, home visit that is made. When you go in and see that a bathroom needs to be adapted, we go there and do the orientation. But we do not have the support behind the institution, it is more a question of the server itself. (122)

I have no way of assessing the other teams [...] I can speak more for my team, I cannot assess the other teams because we do not have so much contact. (117)

Finally, lack of training for patient involvement in care, in order to increase the safety of the proposed treatment/care plan, was also revealed in the speeches as an intervening factor:

They look at patients, but sometimes a more clinical and more accurate look is missing. So, in fact, the team that has to be worked on there is. (I14)

Most of them have no training for this. So, I still think that here in the unit it is still a little deficient for this. (113) 
I have no course, nothing related to that, but we try to make the most of the rush. (I10)

\section{Patient involvement strategies in care safety}

The main strategy for involving patients in care safety, revealed in the speeches, was communication between the actors involved. They highlighted the importance of giving patients a voice, maintaining a horizontal dialogue and simple language:

[...] issue of a conversation, of an open dialogue, a space for listening that they have the courage to tell, to know that they will not be criticized, even the goals they didn't achieve [...] / try to provide an environment that the people have a real conversation and that I'm not here as the holder of knowledge. (I22)

Through dialogue and conversation, I try to explain. Patients sometimes do not know how to read, they draw. Look, take a morning sun, a night sun, a moon light. (I10)

Respect for listening to patients. There is no service where you speak and do not listen, [...] you give them the opportunity to speak and other things appear that you have to intervene. (108)

I develop a strategy with a simple language of how they should take a medication, why they are using it, what would happen if they did not use it properly [...] / reinforce it, l ask them to repeat after me if they understood, how they will use it, what they have to do. (102)

Another strategy used by health professionals, which helps the communication process is the use of printed material and other visual aids:

I try to use a lot of leaflets. I try to use it a lot even for pregnant women with toxoplasmosis, because there is a lot, it is a lot of information, and patients, only at this moment here, they cannot record [...] there is even an issue of insulin, the little thing that shows where they should apply, very didactic, visual things. Sometimes patients, when they are illiterate, when they have a lot of medication, I make a schedule, a table scheme. (I17)

The health care groups were raised as an engagement strategy because it consists of a space for the exchange of experiences among patients and they feel more motivated to talk about their health and adopt measures that promote changes in their health. They were also highlighted for allowing to guide patients and caregivers, obtaining positive results:

Support groups, like "Hiperdia", that they provide support in addition to the office. (I17)

The role of accountability, we work a lot in our team groups, even with great results. We have a patient who managed to reduce medication with the issue of self-care. (108)

The diabetic group, the elderly group. These are things that help them to open up a lot, one speaks the experience to another, and then they see the motivation of the other, and try to motivate themselves too. (106)
Establishing a care plan was considered essential, in the reports of health professionals, to increase patient involvement in issues related to their health:

It depends a lot on patients to understand, absorb and they really want to change, it is what they will do at home that matters. (I17)

[...] Various diseases, such as diabetes, hypertension, these chronic diseases that require changes in diet, changes in daily habits. It depends a lot on patients, so making a care plan to involve patients is very important. (I11)

Bringing the family as a key component for patient involvement in care safety appeared in professionals' reports when patients do not demonstrate the ability to understand the proposed treatment:

[...] when I see that patients do not have much condition to understand what is happening, I ask them to bring a family member, lask them to bring a caregiver. Sometimes we can do it, sometimes we can't. I open more space, when I see that they need it. (I02)

\section{Qualification for patient involvement in care safety}

The qualification for patient involvement in care was associated with academic training and the holding of non-specific workshops and courses:

I have training in family medication, so we go through this. The experience I have here with patients is being valid. (113)

lam a professional who care about my training, so l have done my best for this. I did a specialization, now I'm doing a master's degree [...]. (I12)

For a long time, I participated in the workshops that CONASS held. (I11)

An important aspect that emerged in professionals' speeches is that they feel empowered to involve patients in care due to time of experience with PHC. However, they reveal the need for specific courses to make the practice of involving patients in safe care more incisive, in some specialties:

The experience itself of working a lot with public health, with the community here [...] we need care, specialization, a course. When you talk about alcoholism, I have difficulty dealing with this issue, I think it is very specific. (I18)

I feel [empowered] exactly for that. Throughout our professional lives, we learn, we get trained. (I07)

Another aspect revealed in the speeches is that professionals feel empowered to involve patients in care safety due to the exchange of knowledge that the work environment allows to happen:

The support we have are these courses, these trainings, these discussions that we have with the team, with the colleague on the side, it is for you to clear the doubt. This is what gives me the certainty that I am going the right way. We are taking courses, we are participating, we are exchanging with other colleagues. (107) 


\section{DISCUSSION}

The meaning of patient involvement for care safety was associated with patients' co-responsibility. The importance of patient-centered care also emerged and, at the same time, paying attention to their ability to self-manage the health process, especially for identifying risks and injuries.

The third global challenge, launched by the World Alliance for Patient Safety, brings the empowerment of patients, families and caregivers as one of its objectives ${ }^{(16)}$. This axis of action aims to make patients, family members and caregivers active agents, participative in care and co-responsible in health decisions, helping to identify errors and manage their own care ${ }^{(16)}$. Despite being an initiative focused on reducing medication-related damage, it can be said that patient empowerment must occur in all dimensions and complexity of care.

From this perspective, instruments to assess patients' capacity to cope with the health-disease process and the level of activation for self-management of care have been developed ${ }^{(17-18)}$. Incorporating such instruments in the PHC work routine can help health professionals to develop more specific and individualized actions to assist patients in understanding their role in the health-disease process and, consequently, generate better care results and less risk of damage.

It is important to highlight that health professionals need to know the level of literacy of their patients, in order to facilitate the exchange of information ${ }^{(19)}$. Several studies link low or inadequate health literacy to difficulties in understanding and processing health information, reflecting low knowledge for managing the state of the disease and worse health outcomes ${ }^{(19-20)}$.

Involving patients in care can positively contribute to health literacy and assist patients in coping with the health-disease process. In an environment designed to solve $85 \%$ of the population's health problems ${ }^{(21)}$, the practice of involving patients in care for care safety and obtaining better health results is an urgent need.

Strategies used by health professionals to promote patient involvement in care were highlighted: open communication between patient and health professional, the realization of educational groups, the use of printed resources, the development of a care plan with patient and family/caregiver involvement. They recognized as factors that can interfere in patient involvement for their own safety the bond established between patient and health professional, the care model, social determinants, the culture of medicalization, the influence of popular knowledge, organizational support, and professional training.

Among the factors that interfere with patient-centered care and, consequently, in patient involvement in care safety, the individual characteristics of those involved (patients and professionals) and organizational aspects, such as process and workload, infrastructure are listed for preservation of privacy, hierarchy of professional relationships, and knowledge asymmetry ${ }^{(22)}$.

It is noticed, therefore, that the interferences for the effective practice of patient involvement in care safety are related to aspects of patients, health professionals and the health organization. This reflects the need for cultural changes within the health system and its relationship with users, considering the already existing guiding instruments. The Brazilian National Humanization Policy (Política Nacional de Humanização) ${ }^{(23)}$ stands out, which encourages qualified listening, expanded clinic and health education, which favors individualized care and converges with patient-centered care. More specifically, the guide "Pacientes pela segurança do paciente em serviços de saúde: Como posso contribuir para aumentar a segurança do paciente?", developed by the Brazilian National Health Surveillance Agency (Agência Nacional de Vigilância em Saúde), which guides cultural changes in health regarding patient participation in care safety processes ${ }^{(24)}$. It is pertinent to highlight that the mention of such instruments was not identified in health professionals' reports.

Among the obstacles to non-involvement of patients in care, literature highlights limited knowledge on the subject of patient safety, misinformation regarding specific techniques for patient involvement in their safety and concern about possible negative influence on the professional-patient relationship ${ }^{(13)}$.

It is important to consider the biopsychosocial indicators that patients have ${ }^{(18,25)}$. We highlight the need to identify patients hearing capacity, include family participation in care, adapt communication to patients' and family's needs, establishing an approach centered on patient and family ${ }^{(25)}$. Family members, companions and caregivers as a support network for patients have been shown to be essential for helping to cope with the health-disease process and understanding patients' preferences and concerns, contributing to patient safety ${ }^{(26)}$.

One of the premises for patient involvement in care is professional-patient interaction, with an emphasis on communication. Poor communication between professionals, family members, caregivers and patients causes a large part of incidents in primary care, especially in the use of medications ${ }^{(4)}$. Developing effective communication actions by health professionals among themselves and with patients/companions is a necessity, as well as the involvement of patients in health decisions ${ }^{(22)}$.

It appears that incidents related to care safety happen more frequently at patients' homes ${ }^{(7)}$. Patients must perceive and act on the risks involved in their health-disease process, and health professionals' role is to develop patients' autonomy for self-management of care ${ }^{(18,23)}$, as well as for the identification of possible risks related to the proposed treatment. Improving self-management of health care by patients requires that health professionals even recognize information-seeking behaviors, discuss the information offered by patients and direct them to reliable and accurate sources ${ }^{(18)}$, ensuring care safety.

In this perspective, the unique therapeutic plan stands out, which consists of a set of therapeutic approaches articulated and agreed upon between patient, professional and/or family that considers the resources of the team, the territory, the family and the subject ${ }^{(27)}$. The project seeks the uniqueness of care, interprofessionally and articulately with patients and family members and encourages patients' autonomy and leading role ${ }^{(27)}$. The appropriation of this tool by health professionals can favor the practice of patient involvement in issues related to their own care.

The qualification for patient involvement in care safety was associated with academic training, professional experience, and organizational learning. The work process of the studied setting is developed by health professionals with a diversified profile, time of experience and varied qualifications. Knowing the profile of these professionals offers the health institution the opportunity to explore the breadth of knowledge, experience and talents that each professional brings to the work environment. 
As it is a setting for collaborative practice, $\mathrm{PHC}$ allows sharing interprofessional knowledge and constructing patient-centered therapeutic projects and actions, bringing beneficial results for both the service and users, who enjoy the transdisciplinary cooperation of care ${ }^{(28)}$.

This movement of knowledge exchange among health professionals is extremely important for the resolution of problems on-site and can be favorable to incorporating the practice of patient involvement in care safety in the institutional culture. Thus, the method of sharing experiences in permanent education in health (PEH) that benefits the work process through discussions, support from the team in times of difficulty or doubt and joint decision-making stands out ${ }^{(29)}$. It also provides a critical view of the work process, generating reflection on the performance and situation of the service, encouraging the promotion of continuous improvements in processes ${ }^{(29)}$.

The reports showed that health professionals involve patients in care; however, using strategies considered effective for this practice was not observed. The teach back technique has been shown to be promising in the primary care setting, being associated with strengthening patient-centered communication and increasing the affective involvement of the assisted individual(30). Autonomous medication management and the reporting of incidents by patients have also been encouraged ${ }^{(31)}$, and there is a need to encourage developing these strategies in primary care systematically and qualifiedly.

The existence of gaps in specific training process for patient safety and patient involvement in care was identified in the reports. The qualification of professionals benefits the context of the work around them, generating greater quality for their daily practice, supported by scientific evidence ${ }^{(29)}$. Education allows moments of reflection on service and professional practice, enabling professionals to become agents of change in institutional culture ${ }^{(28)}$.

Therefore, the institutional offer of professional improvement on strategies for patient involvement in care can help strengthen the culture of safety and patient involvement in the context of PHC. Safety culture is defined as a result of interaction between individual and group values, attitudes, perceptions, skills and behavior patterns that determine the commitment to the management of health and organizational safety. Institutions with a strong safety culture are characterized by communication based on mutual trust, shared perceptions about the importance of safety and, still, by the belief in the effectiveness of preventive measures ${ }^{(32)}$.

It is considered that the studied environment is favorable to organizational changes, since professionals recognize the factors that interfere in patient involvement during professional practice. It is noteworthy that in order to promote changes in the work environment, it is essential to assess the safety culture in order to provide a basic understanding of the perceptions of health professionals related to safety in $\mathrm{PHC}^{(33)}$.

Often, assessments of the safety culture in PHC environments have shown, as points in need of improvement in services, the decision based on scientific knowledge, individualization of care, consideration of patients' needs and values ${ }^{(33)}$, among other factors. These are problems, therefore, that must be solved by the health team in order to expand patients' problem-solving capacity, considering $\mathrm{PHC}$ principles.
Despite not being a systematic and effective practice, it was found that, from the perception of many of health professionals who participated in this study, patient involvement in care takes place. Organizational support for learning is understood as a series of encouragement of organization that favors individuals'learning at work $^{(34)}$. From this perspective, generating such stimuli can facilitate developing new skills related to patient involvement for care safety and its application in the daily practice of $\mathrm{PHC}$ health professionals, including those who have not yet developed it.

It is worth mentioning that the practice of patient-centered care, which includes patient involvement for care safety, is still incipient and encounters obstacles in the Brazilian health system ${ }^{(35)}$. However, patientcentered care and safety are inseparable practices in the context of quality in health, and it is indisputable that the involvement of patients and their family members/companions in planning and execution of health care is an important strategy for preventing incidents ${ }^{(22)}$.

\section{Study limitations}

The limitations of this study are related to the method of obtaining the data, since interviews can inhibit participants from expressing their real perceptions. However, it is considered that there was no damage to achieving the proposed objective.

\section{Contributions to nursing, health, or public policy}

The study's contributions to nursing and health are about the need to qualify the practice of patient involvement for care safety so that strategies used by professionals are effective and result in improvements in $\mathrm{PHC}$ care indicators. The results also reveal the need to develop research to analyze the organizational culture for the practice of patient involvement in care safety and to assess effective patient involvement practices as well as their impact on the resolution and safety of health care. Another important research perspective is to reveal how patients assisted in $\mathrm{PHC}$ sees itself in this process of involvement and self-management of care.

\section{FINAL CONSIDERATIONS}

The meaning of patient involvement for care safety was associated with co-responsibility. Patient-centered care brought a relevant perspective to patient involvement in care, since this process requires from health professionals to understand patients' real needs. It was evidenced that patient involvement is important for care safety because it promotes patients' commitment to issues related to their own care.

The factors involved in patient involvement in care safety highlighted by health professionals were related to aspects of patients, health professionals and the health organization itself.

The strategies used by health professionals to encourage patient involvement in care were open communication between patient and health professional, educational groups, verbal guidelines associated with using printed/visual resources, development of patient care plan and family/caregiver involvement.

Despite not having received a course on patient safety at the work unit, professionals reported that they feel empowered to involve patients in care safety due to academic training, professional experience, and organizational learning. 


\section{REFERENCES}

1. World Health Organization (WHO). World alliance for patient safety. Taxonomy: the conceptual framework for the international classification for patient safety[Internet]. Genebra WHO. 2009 [cited 2019 Nov 5]. 154p. Available from: https://www.who.int/patientsafety/taxonomy/ icps_full_report.pdf

2. World Health Organization (WHO). Word alliance for patient safety. Forward program 2006-2007[Internet]. WHO Genebra; 2007 [cited 2020 Feb 15]. Available from: http://www.who.int/patientysafety

3. Baker GR, Norton PG, Flintoft V, Blais R, Brown A, Cox J, et al. The Canadian adverse events study: the incidence of adverse events among hospital patients in Canada. CMAJ [Internet]. 2004 [cited 2020 Feb 15];170(11):1678-86. Available from: http://www.cmaj.ca/ content/170/11/1678.full

4. Rees $\mathrm{P}$, Edwards A, Powell $\mathrm{C}$, Hibbert $\mathrm{P}$, Williams $\mathrm{H}$, Makeham $\mathrm{M}$, et al. Patient safety incidents involving sick children in primary care in England and Wales: a mixed methods analysis. PLoS Med. 2017;14(1):1-23. https://doi.org/10.1371/journal.pmed.1002217

5. Organization for Economic Cooperation and Development. The economics of patient safety in primary and ambulatory care: flying blind. OECD [Internet]. 2018 [cited 2019 Nov 24]. 49p. Available from: https://www.oecd.org/health/health-systems/The-Economics-of-PatientSafety-in-Primary-and-Ambulatory-Care-April2018.pdf

6. Marchon SG, Mendes JWV, Pavão ALB. Characteristics of adverse events in primary health care in Brazil. Cad Saúde Pública. 2015;31(11):2330-13. https://doi.org/10.1590/0102-311x00194214

7. Aguiar TL, Lima DS, Moreira MAB, Santos LF, Ferreira JMBB. Patient safety incidents in Primary Healthcare in Manaus, AM, Brazil. Interface (Botucatu) [Internet]. 2020 [cited 2020 Oct 27];24(Suppl 1):e190622. https://doi.org/https://doi.org/10.1590/interface.190622

8. World Health Organization (WHO). Safer Primary Care Expert Working Group[Internet]. Geneve: WHO. 2012 [cited 2020 May 21]. Available from: http://www.who.int/patientsafety/safer_primary_care/en/index.html

9. World Health Organization (WHO). Patients for Patient Safety: forward program[Internet]. Genebra (SW): WHO. 2004 [cited 2020 May 21]. Available from: http://www.who.int/patientsafety/patients_for_patient/en/

10. The Health Foundation. Person-centered care made simple: what everyone should know about person-centered care. THF [Internet]. 2016 [cited 2019 Nov 26]. 1-44. Available from: https://www.health.org.uk/sites/default/files/PersonCentredCareMadeSimple_0.pdf

11. Sahlström M, Partanen $P$, Rathert C, Turunen H. Patient participation in patient safety still missing: patient safety experts' views. Int J Nurs Pract. 2016;22:461-9. https://doi.org/10.1111/ijn.12476

12. Rather C, Brandt J, Williams ES. Putting the 'patient' in patient safety: a qualitative study of consumer experiences. Health Expect. 2012;15(3):327-36. https://doi.org/10.1111/j.1369-7625.2011.00685.x

13. Martin HM, Navne LE, Lipczak H. Involvement of patients with cancer in patient safety: a qualitative study of current practices, potentials and barriers. BMJ Qual Saf. 2013;22(10):836-42. https://doi.org/10.1136/bmjqs-2012-001447

14. Fontanella BJB, Luchesi BM, Saidel MGB, Ricas J, Turato ER, Melo DG. Amostragem em pesquisas qualitativas: proposta de procedimentos para constatar saturação teórica. Cad Saúde Pública [Internet]. 2011 [cited 2019 Nov 27];27(2):394-89. Available from: http://www.scielo.br/ $\mathrm{pdf} / \mathrm{csp} / \mathrm{v} 27 \mathrm{n} 2 / 20 . \mathrm{pdf}$

15. Bardin L. Análise de Conteúdo. Lisboa, Portugal: Edições 70; 2002. 225p.

16. World Health Organization (WHO). Medication without harm: WHO global patient safety challenge. Geneva WHO [Internet]. 2017 [cited 2019 Nov 25]. 1-12. Available from: http://apps.who.int/iris/bitstream/10665/255263/1/WHO-HIS-SDS-2017.6-eng.pdf?ua=1

17. Bomba F, Markwart H, Mühlan H, Menrath I, Ernst G, Thyen U, et al. Adaptation and validation of the German Patient Activation Measure for Adolescents with chronic conditions in transitional care: PAM $^{\otimes} 13$ for Adolescents. Res Nurs Health. 2018;41(1):78-87. https://doi. org/10.1002/nur.21831

18. Graffigna G, Barello S, Bonanomi A, Riva G. Factors affecting patients' online health information-seeking behaviours: the role of the Patient Health Engagement (PHE) Model, Patient Educ Couns. 2017;100(10):1918-27. https://doi.org/10.1016/j.pec.2017.05.033

19. Bezerra JNM, Lessa SRO, Ó MF, Luz GOA, Borba AKOT. Health literacy of individuals undergoing dialysis therapy. Texto Contexto Enferm. 2019;28(e20170418). https://doi.org/10.1590/1980-265x-tce-2017-0418

20. Chehuen Neto JA, Costa LA, Estevanin GM, Bignoto TC, Vieira CIR, Pinto FAR, et al. Functional Health Literacy in chronic cardiovascular patients. Ciênc Saúde Coletiva. 2019;24(3):1121-32. https://doi.org/10.1590/1413-81232018243.02212017

21. Mendes EV. A construção social da atenção primária à saúde. Conselho Nacional de Secretários de Saúde - CONASS [Internet]. 2015 [cited 2020 Apr 19]. 1-193. Available from: https://www.conass.org.br/biblioteca/pdf/A-CONSTR-SOC-ATEN-PRIM-SAUDE.pdf

22. Rodrigues JLSQ, Portela MC, Malik AM. Agenda for patient-centered care research in Brazil. Ciênc Saúde Coletiva. 2019;24(11):28. https://doi org/10.1590/1413-812320182411.04182018

23. Ministério da Saúde (BR). Secretaria de Atenção à Saúde. Política Nacional de Humanização da Atenção e Gestão do SUS: Clínica ampliada e compartilhada[Internet]. Brasília: Ministério da Saúde. 2009 [cited 2020 May 28]. Available from: https://bvsms.saude.gov.br/bvs/ publicacoes/clinica_ampliada_compartilhada_2009.pdf 
24. Agência Nacional de Vigilância Sanitária (Anvisa). Pacientes pela segurança do paciente em serviços de saúde: como posso contribuir para aumentar a segurança do paciente? Orientações aos pacientes, familiares e acompanhantes. Brasília: Anvisa; 2017.

25. Campos RTO, Ferrer AL, Gama CAP, Campos GWS, Trapé TL, Dantas DV. Avaliação da qualidade do acesso na atenção primária de uma grande cidade brasileira na perspectiva dos usuários. Saúde Debate. 2014;38(esp):264-52. https://doi.org/10.5935/0103-1104.2014s019

26. Souza LM, Silva MCS, Zavalhia SR, Coppola IS, Rocha BP. Percepção de enfermeiros da Estratégia de Saúde da Família sobre segurança do paciente. J Nurs Health [Internet]. 2018 [cited 2019 Nov 28];8(2):e188205. Available from: https://periodicos.ufpel.edu.br/ojs2/index.php/ enfermagem/article/view/12721/8827

27. Matuda CG, Pinto NRS, Martins CL, Frazao P. Colaboração interprofissional na Estratégia Saúde da Família: implicações para a produção do cuidado e a gestão do trabalho. Ciênc Saúde Coletiva [Internet]. 2015 [cited 2019 Nov 28];20(8):2521-11. Available from: https://www. scielosp.org/pdf/csc/2015.v20n8/2511-2521/pt

28. Pereira Ld'A, Silva KL, Andrade MFLB, Cardoso ALF. Educação Permanente em Saúde: uma prática possível. Rev Enferm UFPE [Internet]. 2018 [cited 2019 Nov 28];12(5):1469-79. Available from: https://periodicos.ufpe.br/revistas/revistaenfermagem/article/download/231116/29010

29. Silva KL, Matos JAV, França BD. The construction of permanent education in the process of health work in the state of Minas Gerais, Brazil. Esc Anna Nery. 2017;21(4):e20170060. https://doi.org/10.1590/2177-9465-ean-2017-0060

30. Badaczewski A, Bauman LJ, Blank AE, Dreyer B, Abrams MA, Stein REK, et al. Relationship between Teach-back and patient-centered communication in primary care pediatric encounters. Patient Educ Counsel. 2017;100(7):1345-52. https://doi.org/10.1016/j.pec.2017.02.022

31. Sharma AE, Rivadeneira NA, Barr-Walker J, Stern RJ, Johnson AK, Sarkar U. Patient engagement in health care safety: an overview of mixedquality evidence. Health Aff (Millwood). 2018;37(11):1813-20. https://doi.org/10.1377/hlthaff.2018.0716

32. Nieva VF, Sorra J. Safety culture assessment: a tool for improving patient safety in healthcare organizations. Qual Saf Health Care [Internet]. 2003 [cited 2020 Nov 02];12(Suppl 2):17-23. Available from: https://qualitysafety.bmj.com/content/qhc/12/suppl_2/ii17.full.pdf

33. Lawati MHAL, Dennis S, Short SD, Abdulhadi NN. Patient safety and safety culture in primary health care: a systematic review. BMC Fam Pract. 2018;19:104. https://doi.org/10.1186/s12875-018-0793-7

34. Correia-Lima BC, Loiola E, Pereira CR, Gondim SMG. Inventário de suporte organizacional à aprendizagem. Rev Adm Contemp. 2017;21(5):710-29. https://doi.org/10.1590/1982-7849rac2017160316

35. Constand MK, MacDemid JC, Bello-Haas VD, Law M. Scoping review of patient-centered care approaches in healthcare. BMC Health Serv Res. 2014;14(1):1-9. https://doi.org/10.1186/1472-6963-14-271 